Prepared for the U.S. Department of Energy under Contract DE-AC05-76RL01830

\title{
EMP Attachment 1 \\ DOE-SC PNNL Site Sampling and Analysis Plan
}

KM Meier

December 2011

Pacific Northwest

NATIONAL LABORATORY

Proudly Operated by Battelle Since 1965 


\title{
DISCLAIMER
}

This report was prepared as an account of work sponsored by an agency of the United States Government. Neither the United States Government nor any agency thereof, nor Battelle Memorial Institute, nor any of their employees, makes any warranty, express or implied, or assumes any legal liability or responsibility for the accuracy, completeness, or usefulness of any information, apparatus, product, or process disclosed, or represents that its use would not inf ringe privately owned rights. Reference herein to any specific commercial product, process, or service by trade name, trademark, manufacturer, or otherwise does not necessarily constitute or imply its endorsement, recommendation, or favoring by the United States Government or any agency thereof, or Battelle Memorial Institute. The views and opinions of authors expressed herein do not necessarily state or reflect those of the United States Government or any agency thereof.

\author{
PACIFIC NORTHWEST NATIONAL LABORATORY \\ operated by \\ BATTELLE \\ for the \\ UNITED STATES DEPARTMENT OF ENERGY \\ under Contract DE-AC05-76RL01830
}

Printed in the United States of America
Available to DOE and DOE contractors from the
Office of Scientific and Technical Information,
P.O. Box 62, Oak Ridge, TN 37831-0062;
ph: (865) 576-8401
fax: $(865) 576-5728$
email: reports@adonis.osti.gov

Available to the public from the National Technical Information Service

5301 Shawnee Rd., Alexandria, VA 22312

ph: (800) 553-NTIS (6847)

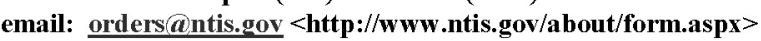

Online ordering: http://www.ntis.gov

This document was printed on recycled paper. 


\section{EMP Attachment 1 DOE-SC PNNL Site Sampling and Analysis Plan}

KM Meier

December 2011

Prepared for

the U.S. Department of Energy

under Contract DE-AC05-76RL01830

Pacific Northwest National Laboratory

Richland, Washington 99352 



\section{Attachment 1 \\ DOE-SC PNNL Site Sampling and Analysis Plan \\ Summary}

This Sampling and Analysis Plan (SAP) is written for the radiological environmental air surveillance program for the U.S. Department of Energy (DOE) Office of Science (DOE-SC) Pacific Northwest National Laboratory Site (PNNL), Richland, Washington. This plan is an attachment to PNNL's Environmental Management Plan (EMP) (PNNL-20919) and addresses a discrete, vital subject area of the EMP that is subject to revision independent of the main text of the EMP document. It provides the requirements for planning sampling events and the requirements imposed on the analytical laboratory analyzing the air samples. The actual air sampling process is found in PNNL procedure EPRP-AIR-029. 



\section{Acronyms and Abbreviations}

$\begin{array}{ll}\text { ARL } & \text { Adjusted Reporting Limit } \\ \text { ASCII } & \text { American Standard Code for Information Interchange } \\ \text { BS } & \text { Blank spike } \\ \text { CFR } & \text { Code of Federal Regulations } \\ \text { COC } & \text { Chain of Custody } \\ \text { DOE } & \text { Department of Energy } \\ \text { DOECAP } & \text { DOE Consolidated Audit Program } \\ \text { DOE-SC } & \text { DOE Office of Science } \\ \text { DQO } & \text { data quality objectives } \\ \text { EMP } & \text { Environmental Management Plan } \\ \text { FEAD } & \text { Format for Electronic Analytical Data } \\ \text { HASQARD } & \text { Hanford Analytical Services Quality Assurance Requirements Documents } \\ \text { LCS } & \text { Laboratory control sample } \\ \text { MAPEP } & \text { Mixed Analyte Performance Evaluation Program } \\ \text { MDA } & \text { Minimum Detectable Activity } \\ \text { MDC } & \text { minimum detectable concentration } \\ \text { MDL } & \text { Method detection limit } \\ \text { NIST } & \text { National Institute of Standards and Technology } \\ \text { PNNL } & \text { Pacific Northwest National Laboratory } \\ \text { PSF } & \text { Physical Sciences Facility } \\ \text { QC } & \text { quality control } \\ \text { RDL } & \text { Required Detection Limit } \\ \text { RPD } & \text { Relative Percent Difference } \\ \text { SAP } & \text { Sampling and Analysis Plan } \\ & \end{array}$





\section{Definitions}

Accuracy - The degree of agreement of a measurement (or an average of measurements of the same thing), $X$, with an accepted reference or true value, $T$, usually expressed as the difference between the two values, $X-T$, or the difference as a percentage of the reference or true value, $100(X-T) / T$, and sometimes expressed as a ratio, $\mathrm{X} / \mathrm{T}$. Accuracy is a measure of the bias in a system. Accuracy represents the degree to which a measurement agrees with an accepted reference or true value. Sample accuracy is expressed as the percent recovery of a spiked sample. Acceptance criteria shall be established for each analyte and each analyte method and shall be agreed on by the laboratory and the client.

Adjusted Reporting Limit (ARL) - If a submitted sample provides less than the aliquot volume/mass required for the analysis requested, the respective required detection limit (RDL) and minimum detectable concentration (MDC) or method detection limit (MDL) may be increased proportionally by the ratio of the volume/mass obtained to the volume/mass expected. This adjusted value is called the Adjusted Reporting Limit (ARL).

Chain of Custody (COC) - An unbroken trail of accountability that ensures the physical security of samples, data, and records. The purpose of the chain-of-custody is to document sample possession and to demonstrate that the sample was maintained in a controlled and unaltered state. This demonstration supports the interpretation of the sample results and may be required in legal proceedings, and for a number of other purposes. Custody in the laboratory is defined as secured to prevent tampering and may be accomplished by having the sample in one of the following situations: 1) in actual physical possession, 2) in view of the sample custodian after being in physical possession, 3) in a locked area, or 4) in a designated secured area (e.g., accessible only to authorized personnel).

Composite - A single sample comprised of samples from two or more sampling periods selected to represent the material being analyzed. Composites combine samples from a single sampling location, unless otherwise indicated.

Laboratory Control Sample (LCS) - A laboratory control sample (LCS) or blank spike (BS) is used to monitor the effectiveness of the sample preparation method. The laboratory control sample is a material similar in nature to the sample being processed containing the isotope(s) of interest (e.g., standard reference material). An LCS, if available, shall be prepared with each batch of samples processed at the same time. The BS is distilled or deionized water, or other suitable substrate spiked with the isotope(s) of interest. The blank, spiked with tracer would also meet the BS requirements. A BS is normally used when an appropriate laboratory control sample is unavailable.

Calculate as

$$
\% R=\frac{(S S R-S R)}{S A} * 100
$$

where $\quad$ SSR $=$ spiked sample result

$\mathrm{SR}=$ sample result

$\mathrm{SA}=$ spike added

$\mathrm{R}=$ recovery. 
Laboratory duplicate - An initial subsample of a sample that has been homogenized, further divided into two separate subsamples, and then subjected to the entire analytical procedure after being received by the laboratory. This is used to determine the precision of a method, expressed as relative percent difference between the two measurements.

Calculate as

$$
R P D=\frac{\left|x_{1}-x_{2}\right|}{\bar{x}} * 100=\frac{2 *\left|x_{1}-x_{2}\right|}{\left|x_{1}+x_{2}\right|} * 100
$$

where $\quad \mathrm{x}_{n}=$ observed value of subsample $n$ $\mathrm{RPD}=$ relative percent difference.

Laboratory or preparation blank - An analytical control prepared by the laboratory, containing distilled, deionized water and reagents, that is carried through the entire analytical procedure (digested and analyzed) concurrently with samples per each sample deliverable group. An aqueous method blank is treated with the same reagents as a sample with a water matrix. A solid method blank is treated with the same reagents as a soil sample. It is a test for contamination in sample preparation and analyses.

Matrix - The component or substrate (e.g., surface water, drinking water) that contains the analyte of interest.

Matrix spike (MS) - An aliquot of a sample spiked with known quantities of compounds and subjected to the entire analytical procedure after being received by the laboratory. The matrix spike duplicate provides the accuracy of a method and is expressed as relative percent difference of the two measurements.

Calculate as

$$
\% R=\frac{(S S R-S R)}{S A} * 100
$$

where

$$
\begin{aligned}
\mathrm{SSR} & =\text { spiked sample result } \\
\mathrm{SR} & =\text { sample result } \\
\mathrm{SA} & =\text { spike added } \\
\mathrm{R} & =\text { recovery. }
\end{aligned}
$$

Matrix spike duplicate (MSD) - A second aliquot of the same sample as the matrix spike, with the same known quantities of compounds added as the matrix spike and subjected to the entire analytical procedure with the matrix spike.

Calculate as

$$
R P D=\frac{\left|x_{1}-x_{2}\right|}{\bar{x}} * 100=\frac{2 *\left|x_{1}-x_{2}\right|}{\left|x_{1}+x_{2}\right|} * 100
$$

where $\quad \mathrm{x}_{n}=$ observed value of the spiked sample $n$ $\mathrm{RPD}=$ relative percent difference. 
Method detection limit (MDL) - The minimum concentration of a compound that can be measured and reported with $99 \%$ confidence that the value is above zero.

Minimum Detectable Activity (MDA) - The smallest amount of activity that can be quantified by laboratory instruments for comparison with regulatory limits.

Minimum Detectable Concentration (MDC) - The minimum detectable activity (MDA) has been defined as a level of activity that is practically achievable by a measurement system. The sample MDA generally is applied as the mean (expected) activity of samples having a $5 \%$ probability of escaping detection and 5\% probability of false detection. The MDA is calculated based on Currie's (1968) formula and is simplified to the following equation when the counting time in the sample is the same as in the background. The MDC is defined as the mean concentration of samples having a 5\% probability of escaping detection and 5\% probability of false detection. The MDC is calculated as

$$
M D C=\frac{M D A}{q * Y * \operatorname{decay}}
$$

where $\quad \mathrm{q}=$ sample quantity (e.g., g or $\mathrm{ml})$

$\mathrm{Y}=$ chemical yield

decay $=$ decay factor (correction for radioactive decay to reference date).

Precision - A measure of the mutual agreement among individual measurements of the same property, usually under prescribed similar conditions. Various measures of precision exist depending on the "prescribed similar conditions." Precision represents a measure of the degree of reproducibility of measurements under prescribed similar conditions. Sample precision is calculated on the basis of duplicate analyses. Acceptance criteria shall be established for each analyte and each analyte method and shall be agreed on by the laboratory and the client.

Relative Percent Difference (RPD) - The RPD applies only to laboratory quality control data and is used when two measurements exist. The RPD is generally used to express the precision of duplicate or spike duplicate samples. The RPD is computed using the following equation:

$$
R P D=\frac{\left|x_{1}-x_{2}\right|}{\bar{x}} * 100=\frac{2 *\left|x_{1}-x_{2}\right|}{\left|x_{1}+x_{2}\right|} * 100
$$

where $\quad \mathrm{x}_{n}=$ observed value of sample $n$ $\mathrm{RPD}=$ relative percent difference.

Quality control (QC) - The overall system of technical activities that measures the attributes and performance of a process, item, or service, against defined standards to verify that they meet the requirements established by the customer. Operational techniques and activities that are used to fulfill requirements for quality.

Required Detection Limit (RDL) - Contractually required detection limit for the analyte of interest. The RDL can be at or above the Method Detection Limit. 
Spike - An aliquot of known concentration of the analyte of interest that is added to a replicate sample undergoing a chemical analysis process for purposes of providing a reference response. Spikes may have additional related terms such as blank spike, matrix spike, carrier, tracer, etc., depending on the intended use.

Uncertainty - A measure of the total variability associated with sampling and measurement that includes the two major error components: systematic error (bias) and random error (imprecision). Uncertainty is expressed as the range of values in which the true value is estimated to lie. Each contributing source of uncertainty (i.e., systematic or random) is expected to be distributed over its range. Each systematic component can be estimated in terms of the measurement result for the contributing source of uncertainty. The analytical systematic component can be estimated using standard or spike recovery. The random analytical component can be estimated from replicate measurements of a sample. The total uncertainty is calculated as the square root of the sum of the squares of random and systematic variabilities. The component of uncertainty has to be expressed in the same unit designation (e.g., concentration percentage). 


\section{Contents}

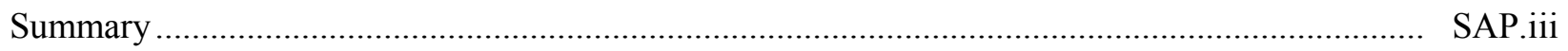

Acronyms and Abbreviations .......................................................................................... SAP. S

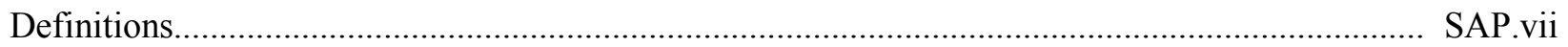

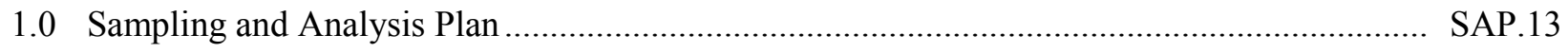

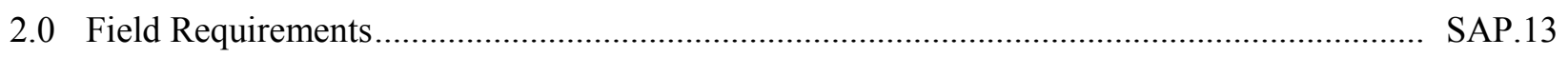

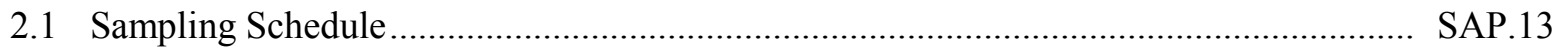

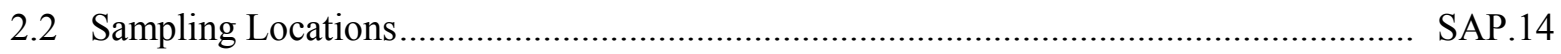

2.3 Sampling Equipment ...................................................................................... SAP. 14

2.4 Sample Collection Matrix and Collection Process ...................................................... SAP.15

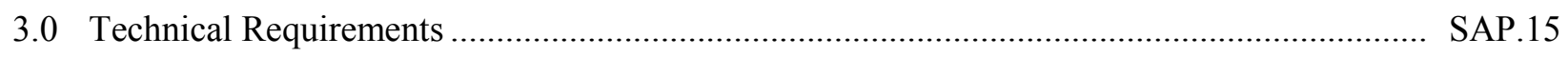

3.1 Laboratory Required Qualifications ..................................................................... SAP.15

3.1.1 Assessment and Intercomparison Programs ................................................... SAP.15

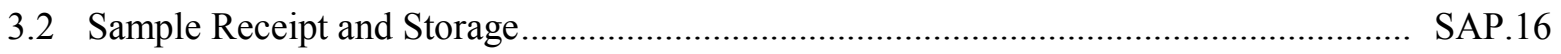

3.2.1 Sample Receipt - Verification and Chain of Custody.................................... SAP.16

3.2.2 Gross Alpha/Gross Beta Analyses ……......................................................... SAP.17

3.2.3 Compositing of Samples ......................................................................... SAP.17

3.2.4 Sample Preparation .............................................................................. SAP. 17

3.2.5 Sample Storage and Disposal .................................................................. SAP.17

3.3 Sampling Devices Prepared at the Analytical Laboratory ............................................. SAP.18

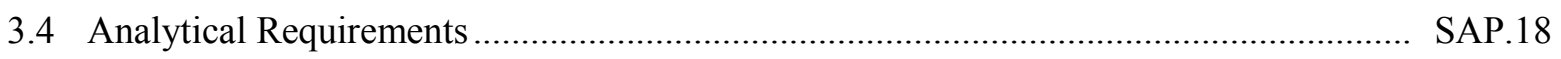

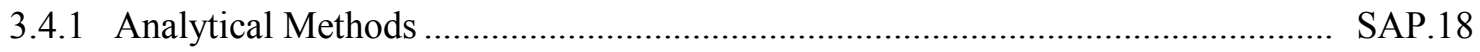

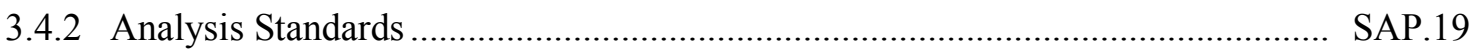

3.4.3 Sample Units ........................................................................................ SAP.19

3.5 Method Detection Limits and Required Reporting Limits........................................... SAP.19

3.6 Rechecks, Recounts, and Reanalysis....................................................................... SAP.19

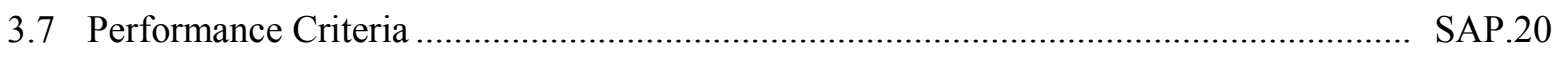

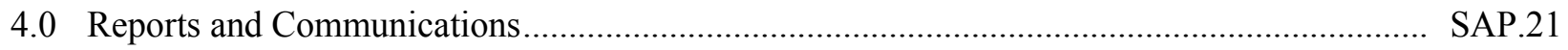

4.1 General Notification Requirements ...................................................................... SAP.21

4.2 Routine and Priority Processing Reporting Times ..................................................... SAP.21

4.3 Analytical Data Report Deliverable ....................................................................... SAP. 22

4.3.1 Hardcopy Report …................................................................................ SAP.22

4.3.2 FEAD Electronic Format ....................................................................... SAP.23

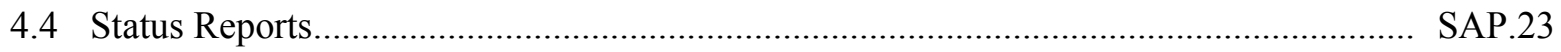

4.5 Notification of Unusual Test Results ……......................................................... SAP.23

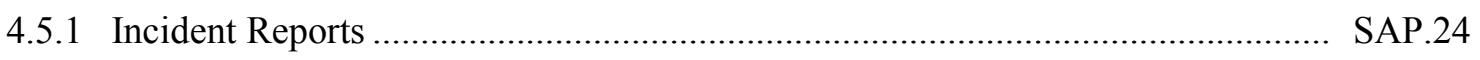

DOE-SC PNNL Site EMP Attachment 1 (Dec 2011) S SAP.xi 


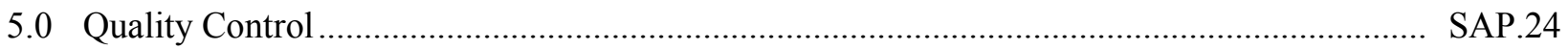

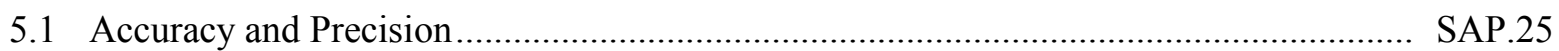

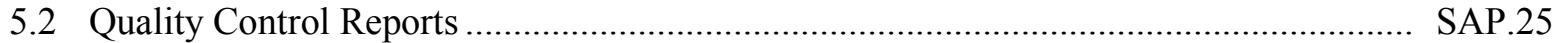

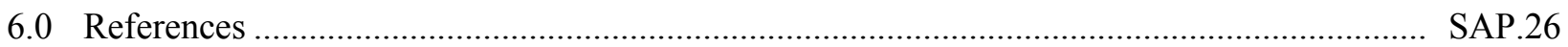

Appendix A - Filter Assembly Process ........................................................................................ SAP.27

\section{Figure}

1 Air Sampling Systems for Radioactive Particulates

SAP.14

\section{Tables}

1 Contract Required Reporting Limits for the Radionuclide Analyses …................................ SAP.16

2 Analytical Methods for the Radionuclide Analyses of Air Samples ..................................... SAP.18

3 Reporting Times for Routine and Priority Processing of Samples ........................................ SAP.21

4 Contract-Specific Accuracy and Precision Requirements for Radiochemical Analyses .......... SAP.25 


\subsection{Sampling and Analysis Plan}

This Sampling and Analysis Plan (SAP) covers the radiological air environmental surveillance activities for the U.S. Department of Energy (DOE) Office of Science (DOE-SC) Pacific Northwest National Laboratory Site (DOE-SC PNNL Site). Sampling and analysis activities for the DOE-SC PNNL Site are managed by PNNL. PNNL performs these tasks under contract DE-AC05-76RL01830 for the DOE-SC. Presently, the following facilities are located on the DOE-SC PNNL Site: the Physical Sciences Facility (PSF) (3410, 3420, 3425, and 3430 Buildings) and the Environmental and Molecular Sciences Laboratory (3020 Building).

The rationale for analyte selection, media, and sampling site location has been vetted through the data quality objectives (DQO) process (Barnett et al. 2010). The results from the DQO process have been reviewed and approved by the Washington State Department of Health.

The DQO process (Barnett et al. 2010) identified seven specific radionuclides for analysis along with the need for gross alpha and gross beta radiological analyses. The analytes are ${ }^{241} \mathrm{Am},{ }^{243} \mathrm{Am},{ }^{244} \mathrm{Cm}$, ${ }^{60} \mathrm{Co},{ }^{238} \mathrm{Pu},{ }^{239} \mathrm{Pu}$, and ${ }^{233} \mathrm{U}$.

The report also determined that air samples for particulates are the only sample matrix required for the monitoring program. These samples are collected on 47-mm glass-fiber filters.

\subsection{Field Requirements}

Sampling and analysis for radiological environmental air surveillance of the DOE-SC PNNL Site air emissions requires field and subsequent sample handling activities. The field requirements include those from scheduling sample collection through the actual collection steps.

\subsection{Sampling Schedule}

A sampling schedule will be prepared by the PNNL Effluent Management group and maintained on the Effluent Management internal website. Based on the annual design review, the sampling schedule may be updated on a less than annual bases. All environmental air monitoring samples are collected on a biweekly schedule and sent to the analytical laboratory for analysis or retained there for compositing and/or disposal.

Air sampling locations are visited every other week. Experience indicates that air-particulate glassfiber filters must be collected at this frequency to avoid occasional excess particulate buildup on the filters. Following collection, each particulate sample is analyzed for gross alpha and for gross beta to provide an early indication of any unplanned contaminant release that may require expedited analysis of samples and/or additional or special sampling. Biweekly filter samples from a single location are composited at the analytical laboratory for quarterly analysis (gamma emitters, uranium isotopes, plutonium isotopes, and americium isotopes) to track trends that are not likely to be detectable by the gross activity measurements. Radiochemical analyses of filters are performed quarterly to provide data to confirm (low) emissions. 


\subsection{Sampling Locations}

There are three sampling locations located adjacent to the DOE-SC PNNL site (see Environmental Monitoring Plan [EMP], Figure 2.1). The two northern monitoring stations, PNL-1 and PNL-2, are colocated with the two existing DOE Hanford Site 300 Area air monitoring locations N and NNW of the PSF. A third site, PNL-3, was established at the DOE-SC PNNL Site maximally exposed individual ${ }^{1}$ location SE of the PSF (Barnett et al. 2010).

\subsection{Sampling Equipment}

The following equipment and supplies may be needed when collecting air-particulate samples:

- Clean filter-head assemblies (in plastic jars with lids) with filters already installed.

- A calibrated air flow meter.

- Rain guards (hoods) for filter holders.

- Plastic tubing (3/8 and $1 / 2$ inch inner diameter) for tubing repairs.

- Hose clamps (large and small, plastic and metal).

- Spare vacuum pump, air flow controller, air volume totalizer.

- Assorted tools for minor repairs.

- Sample labels, Sample Collection Record, and Chain-of-Custody forms.

- Lubricant (for hutch locks).

- Insecticide for bees and wasps in air hutches.

Figure 1 provides a schematic of an air sampling system. Sampling inlets are located two meters above the ground to provide measurements representative of radionuclide concentrations inhaled by humans. The data affecting flow-controller is verified against a National Institute of Standards and Technology (NIST) traceable calibrated flow meter when staff exchanges filter assemblies.

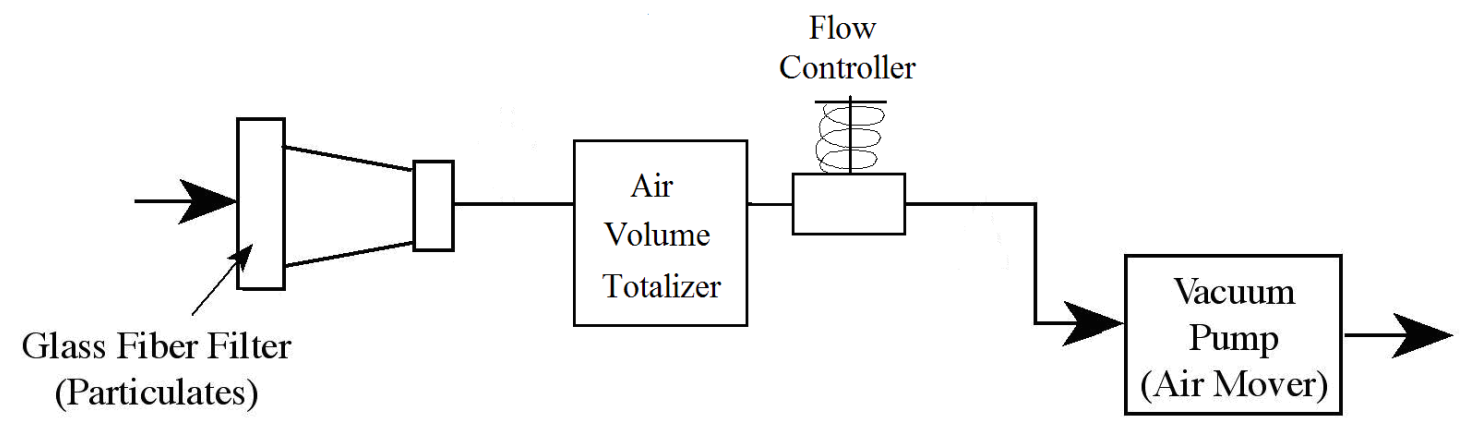

Figure 1. Air Sampling Systems for Radioactive Particulates

\footnotetext{
${ }^{1}$ Maximally exposed individual based on 24 years of meteorological data.
} 


\subsection{Sample Collection Matrix and Collection Process}

Air is pulled through a filter head assembly containing a 47-mm glass-fiber filter at a rate of approximately $1.5 \mathrm{cfm}\left(\sim 2.55 \mathrm{~m}^{3} / \mathrm{hr}\right)$ at the sampling station. This provides approximately an air volume of $860 \mathrm{~m}^{3}$ for a 2-week time period. At the flow rate used, the filters have a sampling efficiency of at least $99 \%$ for 0.3 -micrometer-diameter particles. Flow rates for particle filters are checked and readjusted (if needed) at the end of the sampling period and sample volumes are measured with a calibrated in-line dry-gas meter.

During sample collection, the sampler removes the exposed particulate filter-head assembly and replaces with a new filter-head assembly. The exposed filter-head assembly is carefully placed in a storage jar, filter paper facing up. The staff enters all pertinent sampling information on the forms and on the sample label and places the appropriate sample label inside the sampling jar.

The staff shall assure the security and integrity of all samples up until the time they are relinquished to the analytical laboratory. At the completion of the sampling activities, the sampler returns the original field paperwork to the Data Management Engineer to assure proper sample tracking.

\subsection{Technical Requirements}

The field work ends when the sampler relinquishes samples to the contracted analytical laboratory and returns the completed field paperwork to the Data Management Engineer. The following sections summarize the analytical laboratory's responsibilities in handling the DOE-SC PNNL Site radiological environmental air surveillance samples.

\subsection{Laboratory Required Qualifications}

PNNL will contract with an analytical laboratory that is either listed on the PNNL Evaluated Supplier List, has been evaluated by DOE Consolidated Audit Program (DOECAP), or is accredited as testing laboratory by the American Association for Laboratory Accreditation or National Voluntary Accreditation Program. An analytical laboratory that performs work to the Hanford Analytical Services Quality Assurance Requirements Documents (HASQARD), Rev. 3 (DOE 2007), would be acceptable, too. The Statement of Work with the laboratory shall contain the requirements from this SAP and shall be kept current to any relevant revisions of the EMP.

\subsubsection{Assessment and Intercomparison Programs}

The analytical laboratory shall participate in the DOE Mixed Analyte Performance Evaluation Program (MAPEP) program. The laboratory shall analyze all MAPEP samples received for those radionuclides that are requested for the analytes and their respective analytical method, as indicated in Table 1. The Required Detection Limits (RDLs) specified in Table 1 shall apply, and the procedures outlined in this SAP shall be used unless exceptions are granted in writing by PNNL. 
Table 1. Contract Required Reporting Limits for the Radionuclide Analyses

\begin{tabular}{|c|c|c|c|}
\hline $\begin{array}{c}\text { Analyte of } \\
\text { Interest }\end{array}$ & $\begin{array}{c}\text { Contract Required } \\
\text { Detection Limit } \\
{\left[\mathrm{pCi} / \mathrm{m}^{3}\right]}\end{array}$ & $\begin{array}{l}\text { Notification } \\
\text { Value }^{(\mathrm{a})} \\
{\left[\mathrm{pCi} / \mathrm{m}^{3}\right]} \\
\end{array}$ & Additional Comments \\
\hline Gross Alpha & 0.0010 & -- & Bi-weekly sample, based on $800 \mathrm{~m}^{3}$ volume \\
\hline Gross Beta & 0.0030 & -- & Bi-weekly sample, based on $800 \mathrm{~m}^{3}$ volume \\
\hline${ }^{241} \mathrm{Am}$ & 0.000050 & 0.00019 & Quarterly Composite, based on $500 \mathrm{~m}^{3}$ volume \\
\hline${ }^{243} \mathrm{Am}$ & 0.000050 & 0.00018 & Quarterly Composite, based on $500 \mathrm{~m}^{3}$ volume \\
\hline${ }^{244} \mathrm{Cm}$ & 0.000050 & 0.00033 & Quarterly Composite, based on $500 \mathrm{~m}^{3}$ volume \\
\hline${ }^{60} \mathrm{Co}$ & 0.0015 & 0.00170 & Quarterly Composite, based on $5000 \mathrm{~m}^{3}$ volume \\
\hline${ }^{238} \mathrm{Pu}$ & 0.0000050 & 0.00021 & Quarterly Composite, based on $5000 \mathrm{~m}^{3}$ volume \\
\hline${ }^{239} \mathrm{Pu}$ & 0.0000050 & 0.00020 & Quarterly Composite, based on $5000 \mathrm{~m}^{3}$ volume \\
\hline${ }^{233} U^{(b)}$ & 0.000050 & 0.00071 & Quarterly Composite, based on $1500 \mathrm{~m}^{3}$ volume \\
\hline
\end{tabular}

(a) Notification value is $10 \%$ of the values listed in Table 2, 40 CFR 61, Appendix E.

(b) Currently reported as ${ }^{233} \mathrm{U} /{ }^{234} \mathrm{U}$.

The analytical laboratory shall report results to the intercomparison supplier according to reporting schedules provided by the DOE MAPEP. The laboratory shall provide PNNL with a copy or summary of each report resulting from the participation in the program. The intercomparison reports should be provided as soon as available and should include the resolution/proposed resolution for any identified problems. At a minimum, this summary report shall provide the sample identification number assigned to the performance samples, the analyzed concentrations, ratios, percent differences, as listed in the provider report.

\subsection{Sample Receipt and Storage}

The following subsections describe radiological air sample receipt, documentation, compositing, storage and disposal.

\subsubsection{Sample Receipt - Verification and Chain of Custody}

Environmental air samples will be collected by PNNL and delivered to the analytical laboratory ${ }^{2}$ using standard chain of custody (COC) documentation. The analytical laboratory shall provide a one-point contact that is available during normal business hours to receive additional information and direction about sample analysis, as deemed necessary by PNNL. The analytical laboratory will also be provided a point of contact at PNNL.

Sample collection containers will be provided by PNNL; glass or plastic containers large enough to house one filter-head assembly. The analytical laboratory shall provide containers for appropriate compositing (i.e., combining) of the bi-weekly samples. All samples submitted for analytical testing will be clearly labeled by PNNL. When two or more samples are to be combined for analysis, the components of the composite sample will be identified at the time of delivery of the initial samples, in addition to a

\footnotetext{
${ }^{2}$ Since 2010, the analytical laboratory performing radiological analyses on the DOE-SC PNNL Site air surveillance samples is GEL, under contract 47355.
} 
sample specific composite sheet sent to the analytical laboratory point-of contact. Each sample label will specify at a minimum:

- PNNL sample number as provided to the sampler on the computer-generated COC form

- Date and time of collection.

Upon receipt by the analytical laboratory, sample labels shall be verified with the COC paperwork. Any discrepancies that cannot be resolved shall be reported to PNNL within 24 hours of receipt.

The analytical laboratory shall assure the security and integrity of all samples (initial as well as residual portions); sample extracts and other preparations; and analytical data and results.

\subsubsection{Gross Alpha/Gross Beta Analyses}

The analytical laboratory is scheduled to receive filter samples for gross alpha/gross beta analyses every 2 weeks. Due to the presence of naturally occurring radon decay products, these samples shall remain in their sampling containers for a minimum of 4 days before analysis. After the gross alpha/gross beta analyses, the samples need to be stored for later compositing.

\subsubsection{Compositing of Samples}

Each quarter PNNL will provide to the analytical laboratory site-specific composite sheets with the requested analyses and outline of individual sample numbers that should be composited (combined) to form the quarterly composite. PNNL shall have five (5) business days following the receipt of test results for gross alpha/gross beta samples to review the data before samples can be composited for subsequent analyses.

\subsubsection{Sample Preparation}

Sample preparation methods shall follow the U.S. Environmental Protection Agency established protocols identified in 40 CFR 61, Appendix B, Method 114 or an agreed upon equivalent alternative. Gross alpha and gross beta concentrations are measured by counting an exposed glass-fiber filter on a gas-flow proportional counter. Gamma emitters are measured by combining alpha-beta filters collected during multiple sampling periods and counting them using a hyperpure germanium detector and a multichannel, pulse-height analyzer. After these measurements have been conducted, the glass-fiber filters are chemically leached with acid to extract the analytes of interest. The chemical processing is unique for each isotope; for each isotope a specific scintillation cocktail is needed and is followed by alpha energy analysis for americium, curium, uranium, and/or plutonium, and gamma spectroscopy for the cobalt isotope.

\subsubsection{Sample Storage and Disposal}

Scintillation vials with the sample extracts shall be stored and preserved for at least 17 calendar days after the date the scintillation cocktail was added to the sample. Gross alpha and gross beta samples (planchets) shall be stored and preserved for at least 30 calendar days following reporting of all results. 
These samples are used for the composite samples, and therefore, shall be stored protected from the environment in vented sample containers.

The analytical laboratory shall provide notification to PNNL in writing of any proposed disposal of residual samples or final analytical preparations. PNNL will designate, within 30 calendar days following laboratory notification of intent to dispose of residual samples and final analytical preparations, any residual samples or final analytical preparations to be withheld from disposal. The laboratory shall make such residual samples or final analytical preparations available for pickup by PNNL. The laboratory shall dispose of all residual samples or final analytical preparations not designated to be withheld from disposal or not picked up within 14 calendar days.

\subsection{Sampling Devices Prepared at the Analytical Laboratory}

The analytical laboratory shall return for re-use the following government-owned containers:

Glass-fiber filter assemblies - The laboratory shall provide glass-fiber filters and prepare government-furnished filter assemblies, in accordance with Appendix A, used to collect samples of airborne particulate matter. These assemblies shall be prepared by the analytical laboratory and made available for re-use by PNNL within five (5) business days after laboratory receipt.

\subsection{Analytical Requirements}

Each sample shall be analyzed according to the test(s) ordered on the COC form (when stated), Daily Trip Log Report and/or composite sheet, and as requested by contract between PNNL and GEL.

\subsubsection{Analytical Methods}

The analytical method used for analysis of air samples shall be performed according to 40 CFR 61, Subpart H, "National Emissions Standards for Emissions of Radionuclides Other than Radon from Department of Energy Facilities", Appendix B Method 114 (see Table 2).

Table 2. Analytical Methods for the Radionuclide Analyses of Air Samples

\begin{tabular}{cl}
\hline Analyte of Interest & \multicolumn{1}{c}{ Analytical Method } \\
\hline Gross alpha/gross beta & Gas proportional counter and approximately 100 min counting time \\
${ }^{241} \mathrm{Am}$ & Alpha Spectrometry \\
${ }^{243} \mathrm{Am}$ & Alpha Spectrometry \\
${ }^{244} \mathrm{Cm}$ & Alpha Spectrometry \\
${ }^{60} \mathrm{Co}$ & Gamma Spectrometry \\
${ }^{238} \mathrm{Pu}$ & Alpha Spectrometry \\
${ }^{239} \mathrm{Pu}$ & Alpha Spectrometry \\
${ }^{233} \mathrm{U}^{(\text {a) }}$ & Alpha Spectrometry \\
\hline
\end{tabular}

(a) Currently reported as ${ }^{233} \mathrm{U} /{ }^{234} \mathrm{U}$, using only alpha spectrometry. Also available, upon request, by inductively coupled plasma mass spectrometry to separate ${ }^{233} \mathrm{U}$ and ${ }^{234} \mathrm{U}$, although inductively coupled plasma mass spectrometry detection levels may not be ideal. 


\subsubsection{Analysis Standards}

Gross alpha measurement systems shall be calibrated to standards containing ${ }^{241}$ Am except where specified otherwise for specific analytical methods referenced herein.

Gross beta measurement systems shall be calibrated to standards containing an equilibrium mixture of ${ }^{90} \mathrm{Sr} /{ }^{90} \mathrm{Y}$.

Gamma spectrometry systems shall be calibrated to a NIST traceable mixed gamma standard where applicable (e.g., NIST Standard Reference Material No. 4275c or No. 4276c or equivalent).

\subsubsection{Sample Units}

The laboratory shall perform the analyses and report per each sample (i.e., filter) for gross alpha/gross beta and per total composite sample for the radionuclides in Table 1. The individual sample numbers of the filters used in the composited samples shall be included with the data report. If the laboratory determines that an aliquot is insufficient (e.g., is not representative and that the analysis could be biased), the laboratory shall contact PNNL for instructions on how to proceed. Discrepancies can be discussed in the final report.

\subsection{Method Detection Limits and Required Reporting Limits}

The contract RDLs (Table 1) are based on specific aliquot sizes for various radionuclide analyses and types of samples. If the respective RDL and minimum detectable concentration (MDC) or method detection limit need to be increased, this adjusted value is called the Adjusted Reporting Limit (ARL).

If there is insufficient material to perform all tests ordered for a given sample, the analytical laboratory shall maintain the integrity of the sample and notify PNNL as soon as practicable and request further instruction (also see Section 4.5). The reporting time for the sample shall be adjusted to reflect the revised test order. At any point, the ARL must be below the Notification Value of Table 1. If this is not possible, immediately contact PNNL for directions before proceeding.

The RDL for the gamma scan analysis is for ${ }^{137} \mathrm{Cs}$. Other radionuclides detected in a gamma scan will have detection levels commensurate with counter background, photon yield, and energy as related to the ${ }^{137} \mathrm{Cs}$ analysis.

\subsection{Rechecks, Recounts, and Reanalysis}

Data rechecks, sample recounts, and sample reanalysis shall be performed for routine and priority processing when ordered.

Recheck. The analytical lab shall perform a data recheck of a previously reported result, if ordered. Data rechecks shall consist of a review of calculations, aliquot size, yield, counter background, counting efficiency, and other data pertinent to the reported analytical result and the correct use of such data in the calculation of results by the laboratory. The laboratory shall also review the results of QC samples as well as the results of other samples processed in the same batch. 
The QC sample results and the results of the lab's data recheck evaluation shall be reported to PNNL in writing:

- Within five (5) business days for those initial results reported up to six months prior to the order for a data Recheck, or

- Within ten (10) business days for those initial results reported more than six months prior to the order for a data recheck.

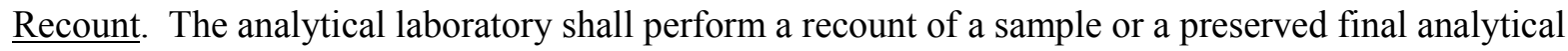
preparation from a sample previously analyzed, if ordered. A recount shall consist of recounting the sample and recalculating the concentration of the radionuclide in question. The laboratory shall report the result of the recount to PNNL in writing within five (5) business days.

Reanalysis. The laboratory shall perform a reanalysis of the preserved unused portion of a sample preparation on a routine or priority basis, when ordered. The analytical requirements listed in Section 3.4 shall apply. The laboratory shall report the results in writing in accordance with Section 4.3.

\subsection{Performance Criteria}

The following performance criteria shall be applied to the reporting of the sample results.

All analytical test results shall be reported as the measured positive or negative value with the associated uncertainties. Details of the reporting requirements are provided in Section 4.0. All measurement uncertainties shall be identified and carried through to the final analytical result. Each report of results shall include estimates of the total propagated analytical uncertainty associated with the determination at the two-sigma level as well as the two-sigma counting uncertainty. The procedures for the determination of uncertainties shall be specified in the analytical lab's analytical test procedures.

The analytical laboratory shall document limits for radioactive contamination allowable in reagents and sample collection media. Blank samples shall be analyzed for each batch of reagents and glass fiber air particulate filters. Such limits shall be consistent with the analytical specifications described in Section 3.5.

The reagent and blank sample collection media data shall be used to determine average batch blank values. The uncertainty of the reagent blank values shall be combined into the total propagated analytical uncertainty.

The analytical laboratory shall maintain records of instrument model number, detection system configuration (generic detector system electronic component schematic including the multi-channel analyzer as applicable), detector bias voltages, calibrated geometries, cross-talk values (if applicable), and detector identifications (if applicable).

The analytical laboratory shall document in their records the vendor supplied analytical peak identification criteria for gamma scan analyses.

The analytical laboratory shall set up instrumentation according to the manufacturer's instructions. Any changes or modifications to the manufacturer's instructions shall be documented for each instrument 
used. Such documentation shall be maintained at the analytical laboratory and available to PNNL upon request.

Counter efficiency, aliquot size, and count duration shall be optimized such that Minimum Detectable Activities/Concentrations (MDAs/MDCs) are at or below the RDLs given in Table 1. Equation 37 from Chapter 6 in EPA 520/1-80-012 (EPA 1980), using the average standard deviation of process blanks for individual methods of interest, shall be used to calculate MDAs/MDCs that demonstrate compliance with the RDLs required for the aliquot sizes shown in Table 1. The process blank computer files shall be updated semi-annually for analytical tests conducted frequently (i.e., gross alpha and gross beta) and at least annually for all other tests.

\subsection{Reports and Communications}

\subsection{General Notification Requirements}

Results shall be stated in $\mathrm{pCi} / \mathrm{m}^{3}$ according to the analytical test ordered, with the number of significant figures appropriate to the measurement process. The air volume will be provided on the COC.

\subsection{Routine and Priority Processing Reporting Times}

All analytical test results for Routine and Priority processing of samples shall be delivered as specified in Table 3 unless a sample maximum requested turnaround time has been negotiated.

PNNL shall have five (5) business days following the receipt of analytical results for air particulate samples to review the data before samples are composited for subsequent analyses. Thus, the reporting timeclock for composite samples shall begin five (5) business days after receipt of gross alpha/gross beta test results for the last sample of the composite.

Reporting times may be extended when sequential analyses are required to perform all tests ordered for a given sample. This will be handled on a case by case basis through documented contact with PNNL.

Table 3. Reporting Times for Routine and Priority Processing of Samples

\begin{tabular}{lcc}
\hline & \multicolumn{2}{c}{ Business Days Following Sample Receipt } \\
\cline { 2 - 3 } \multicolumn{1}{c}{ Type of Analysis } & Routine Processing & Priority Processing \\
\hline Gross Alpha, Gross Beta & 15 & 5 \\
Gamma Spectroscopy & 20 & 10 \\
Uranium, Isotopic & 25 & 15 \\
Curium, Isotopic & 25 & 15 \\
Plutonium, Isotopic & 25 & 15 \\
Americium, Isotopic & 25 & 15 \\
\hline
\end{tabular}




\subsection{Analytical Data Report Deliverable}

A report of analytical data shall consist of:

- A hard copy report and an American Standard Code for Information Interchange (ASCII) File that is fully compatible with the current Format for Electronic Analytical Data (FEAD) electronic format (see Section 4.3.1).

- Results shall be reported with nuclide specific decay corrections applied, when necessary to the date and time of sampling for discrete samples or to the date and time of the sampling mid-point for composited samples obtained over a time interval.

- No changes to the reporting medium or format shall be implemented without the prior written approval of PNNL. The laboratory shall notify PNNL when a change in its reporting software is made (including file naming and format).

\subsubsection{Hardcopy Report}

The following information for each radiochemical test result ordered, in hard copy form, shall be provided, but not limited to:

- Matrix/Media

- Constituent Name

- PNNL Sample Number

- Lab Sample Number

- Analytical Result

- Two-sigma Counting Uncertainty

- Two-sigma Total Propagated Analytical Uncertainty

- Appropriate FEAD Data Qualifier(s)

- Sample On Date (On Time, if available)

- Collection Date (Off Time, if available)

- Sample Aliquot Size/number of filters used

- Sample MDA/MDC

- Analytical Results Units

- Lab Method Number

- Laboratory batch QC results (blanks, duplicates with relative percent difference, tracer and/or spike results and recoveries, laboratory control sample results and recoveries).

- Required Detection Limit

- Adjusted Reporting Limit, if applicable

- Brief Case Narrative that describes any unusual occurrences, procedures, or other comment. 


\subsubsection{FEAD Electronic Format}

The Common Requirements of the Format for Electronic Analytical Data (FEAD) document (CP-15383) describes the format for electronic analytical data deliverables reported by laboratories for loading into the Hanford Environmental Information System. Each test result ordered is reported electronically and must be fully compatible with the current version of FEAD.

\subsection{Status Reports}

If applicable, a Sample Receiving Log Summary Report shall be delivered electronically each week to PNNL. The Sample Receiving Log Summary Report shall specify for each sample:

- PNNL sample number

- PNNL identification number

- Date of sample collection

- Date of sample receipt at the Lab's local receiving facility

- Analytical test result due date

- Each constituent group or individual constituent for which an analytical test was ordered.

A Monthly Not-Reported Results Summary Report of all PNNL samples delivered for analytical test results which are past due shall be delivered to PNNL within five (5) business days following the end of each calendar month. If there are no results to report, a summary report should be provided clarifying such. The Monthly Not-Reported Results Summary Report shall specify for each sample:

- PNNL sample number

- PNNL identification number

- Date of sample collection

- Date of sample receipt

- Constituent for which an analytical test was ordered but not yet reported

- Analytical test results report due date

- Anticipated report date

- Explanation of overdue status.

\subsection{Notification of Unusual Test Results}

The laboratory shall immediately (before the end of the business day) notify PNNL via phone or email in the event of any suspicious or unusual result for any analytical test ordered of any sample.

Upon sample receipt, sample labels shall be verified with the COC paperwork. Any discrepancies shall be reported to PNNL within 24 hours of receipt. 


\subsubsection{Incident Reports}

The laboratory shall immediately (before the end of the business day) notify PNNL via email when:

- The laboratory determines that a correction should be made to a previously reported result.

- Samples submitted for analytical testing have been lost or destroyed.

- There has been a failure to follow approved analytical test procedures (including QC procedures).

- There has been an equipment failure or other loss of capability which has the potential to:

- Adversely affect the accuracy of the analytical test result

- Prevent the delivery of analytical test results within the reporting times specified.

- An audit or management assessment of the adequacy of the laboratory's quality assurance program results in a conclusion that quality assurance requirements have not been met.

- There is any other indication of potential compromise in the quality of analytical test results (including but not limited to failure to meet analytical test specifications) reported or to be reported.

- Each email report shall be followed by a written report within five (5) business days. The written report shall:

- State that the report is made pursuant to this provision.

- Explain in detail the circumstances which necessitate that the report be made, including names and position titles of laboratory and any subcontractor's employees involved.

- Be signed by a representative of the laboratory authorized to enter into legally binding commitments on its behalf.

- Specify the corrective actions the laboratory has taken or plans to take, with the dates the corrective action has or will be completed. If corrective action is not deemed necessary or appropriate, the written report shall explain the reason for such conclusion.

- Be reported as a Comment in the appropriate column(s) specified in FEAD.

\subsection{Quality Control}

The analytical laboratory shall assure the integrity and validity of analytical test results through implementation of an internal QC program. The laboratory's QC Program shall be described in a written procedure(s) and shall include a corrective action system for discrepant results. An effective system for reviewing and analyzing such results shall be maintained to detect problems due to contamination, or inadequate calibrations, calculations, procedures, or other causes. Standard methods shall be used whenever possible and methods that are developed or adapted shall be tested and completely documented by the laboratory.

The laboratory shall prepare and analyze spiked, blank and replicate samples to verify the accuracy and precision of all analytical results. The total number of such samples shall be no less than $15 \%$ of all ordered tests. Spikes shall be included with each batch of samples processed and have, insofar as possible, a matrix, volume, and other relevant characteristics of the actual samples being analyzed. An 
analytical batch shall consist of 20 or less samples. Spiked samples shall have a range of activity from five (5) times the sample result to no greater than ten (10) times the sample result. Reagent and sample matrix blanks shall be analyzed with each batch of samples processed except for gross alpha, gross beta, and gamma analyses where water is used as the blank and spike matrix only.

\subsection{Accuracy and Precision}

The accuracy of the sample collection is specified as follows: if the sampling system collects a sample $85 \%$ or more of the time, it is an acceptable air sample. Details can be found in procedure EPRP-AIR-029.

Accuracy and precision are measured in the analytical laboratory with the aid of blanks, duplicates, and spikes. An analytical batch of samples is defined as not more than 20 samples. When reporting composite results, there shall be at a minimum one blank, one duplicate, and one spike analyzed per analytical batch of samples. When reporting individual air filters results, there shall be one blank analyzed per analytical batch of samples.

Accuracy requirements for the QC samples as listed in Table 4 shall be met by the laboratory control sample and any other spiked sample where the sample concentration is above the RDL and the spiked concentration ranges from five (5) times to no greater than ten (10) times the sample concentration and for duplicate sample results that are greater than the RDL.

Accuracy shall be based on the use of certified standards for each measurement process required to obtain results. The laboratory shall document these results. Analytical problems identified through analysis of QC samples shall be promptly corrected.

\subsection{Quality Control Reports}

Internal laboratory batch QC sample results will be reported in the FEAD format along with sample results.

Table 4. Contract-Specific Accuracy and Precision Requirements for Radiochemical Analyses

\begin{tabular}{llcc}
\hline \multicolumn{1}{c}{ Analysis } & \multicolumn{1}{c}{ Blanks } & $\begin{array}{c}\text { Accuracy for } \\
\text { Spikes } \\
{[\% \text { Recovery }]}\end{array}$ & $\begin{array}{c}\text { Precision for } \\
\text { Duplicates } \\
\text { [STDEV] }\end{array}$ \\
\hline Gamma Spectrometry & $<5 \%$ Notification Level & $80-120$ & $<3$ \\
Liquid Scintillation & $<5 \%$ Notification Level & $80-120$ & $<3$ \\
Liquid Scintillation with Chemical & $<5 \%$ Notification Level & $70-130$ & $<3$ \\
Separation & & & \\
Alpha Spectrometry & $<5 \%$ Notification Level & $75-125$ & $<3$ \\
Beta Proportional & $<5 \%$ Notification Level & $70-130$ & $<3$ \\
Alpha Proportional & $<5 \%$ Notification Level & $70-130$ & $<3$ \\
\hline
\end{tabular}




\subsection{References}

40 CFR 61. 2011. "National Emission Standards for Hazardous Air Pollutants." Code of Federal Regulations, U.S. Environmental Protection Agency.

40 CFR 61, Appendix B. 2011. "National Emission Standards for Hazardous Air Pollutants." Appendix B, "Test Methods." Code of Federal Regulations, U.S. Environmental Protection Agency.

40 CFR 61, Appendix E. 2011. "National Emission Standards for Hazardous Air Pollutants." Appendix E, "Compliance Procedures Methods for Determining Compliance with Subpart I." Code of Federal Regulations, U.S. Environmental Protection Agency.

40 CFR 61, Appendix E, Table 2. 2011. "National Emission Standards for Hazardous Air Pollutants." Appendix E, "Compliance Procedures Methods for Determining Compliance with Subpart I; Concentrations Levels for Environmental Compliance." Code of Federal Regulations, U.S. Environmental Protection Agency.

40 CFR 61, Subpart H. 2011. "National Emission Standards for Hazardous Air Pollutants." Subpart H, "National Emission Standards for Emissions of Radionuclides Other Than Radon from Department of Energy Facilities." Code of Federal Regulations, U.S. Environmental Protection Agency.

Barnett JM, BG Fritz, KM Meier, TM Poston, SF Snyder, and K Rhoads. 2010. Data Quality Objectives Supporting Radiological Air Emissions Monitoring for the PNNL Site. PNNL-19427, Pacific Northwest National Laboratory, Richland, Washington.

CP-15383, Rev. 8. December 2007. Common Requirements of the Format for Electronic Analytical Data (FEAD). CH2M HILL Plateau Remediation Company, Richland, Washington.

DOE - U.S. Department of Energy. 2007. Hanford Analytical Services Quality Assurance Requirements Documents (HASQARD). DOE/RL-96-68, Rev. 3, U.S. Department of Energy, Richland Operations Office, Richland, Washington.

DOECAP program available at https://doecap.oro.doe.gov/DOECAP_Public/.

DOE MAPEP program available at http://www.hss.energy.gov/CSA/Analysis/ASP/mapep.html.

EPRP-AIR-029, Revision 0. Air Particulate Sampling and Routine Maintenance of Environmental Monitoring Stations for the PNNL Site.

EPA - U.S. Environmental Protection Agency. 1980. Upgrading Environmental Radiation Data: Health Physics Society Committee Report HPSR-1. EPA 520/1-80-012, Office of Radiation Programs, U.S. Environmental Protection Agency, Washington, D.C. 


\section{Appendix A}

\section{Filter Assembly Process}





\section{Appendix A}

\section{Filter Assembly Process}

\section{A.1 Glass Fiber Filter Assembly Preparation Process}

\section{A.1.1 Air Particulate Collection Assemblies}

Government-furnished air particulate collection assemblies consist of metal holders. Each filter holder consists of pieces that are threaded, twisted, or snapped together. The unit consists of a larger filter holder body and a retention ring to hold the filter in place.

\section{A.1.2 Preparation Process}

The analytical laboratory shall remove the exposed filter from the filter holder and replace it with the appropriate 47-mm LB.5211 new glass fiber filter. Care shall be taken to place the new filter with the inlet side of the paper facing the inlet side of the filter assembly. Prior to installing the new filter, the analytical laboratory shall inspect the assembly and notify the PNNL Technical Administrator of any damaged or worn seals, damaged, plugged, or flattened filter support screens, or otherwise damaged assemblages. After installation of the new filter, the analytical laboratory shall ensure that the filter retaining ring appears sufficiently tightened to prevent leakage during sampling. The analytical laboratory shall place the filter head assembly in a clear plastic storage jar with cover to protect them from ambient dust until they are deployed. 




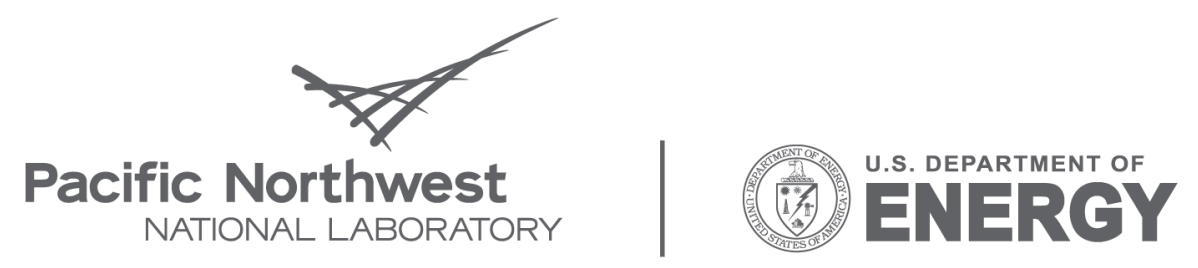

Proudly Operated by Battelle Since 1965

902 Battelle Boulevard

P.O. Box 999

Richland, WA 99352

1-888-375-PNNL (7665)

www.pnl.gov 